\title{
Systematic Radiation Dose Reduction in Cervical Spine CT of Human Cadaveric Specimens: How Low Can We Go?
}

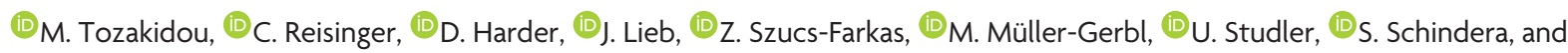 \\ (1) A. Hirschmann
}

\begin{abstract}
BACKGROUND AND PURPOSE: While the use of cervical spine CT in trauma settings has increased, the balance between image quality and dose reduction remains a concern. The purpose of our study was to compare the image quality of CT of the cervical spine of cadaveric specimens at different radiation dose levels.
\end{abstract}

MATERIALS AND METHODS: The cervical spine of 4 human cadavers (mean body mass index; $30.5 \pm 5.2 \mathrm{~kg} / \mathrm{m}^{2} ;$ range, $24-36 \mathrm{~kg} / \mathrm{m}^{2}$ ) was examined using different reference tube current-time products $(45,75,105,135,150,165,195,275,355 \mathrm{mAs})$ and a tube voltage of 120 $\mathrm{kV}$ (peak). Data were reconstructed with filtered back-projection and iterative reconstruction. Qualitative image noise and morphologic characteristics of bony structures were quantified on a Likert scale. Quantitative image noise was measured. Statistics included analysis of variance and the Tukey test.

RESULTS: Compared with filtered back-projection, iterative reconstruction provided significantly lower qualitative (mean noise score: iterative reconstruction $=2.10 /$ filtered back-projection $=2.18 ; P=.003$ ) and quantitative (mean SD of Hounsfield units in air: iterative reconstruction $=30.2$ filtered back-projection $=51.8 ; P<.001$ image noise. Image noise increased as the radiation dose decreased. Qualitative image noise at levels $\mathrm{Cl}-4$ was rated as either "no noise" or as "acceptable noise." Any shoulder position was at level C5 and caused more artifacts at lower levels. When we analyzed all spinal levels, scores for morphologic characteristics revealed no significant differences between 105 and $355 \mathrm{mAs}(P=.555)$, but they were worse in scans at $75 \mathrm{mAs}(P=.025)$.

CONCLUSIONS: Clinically acceptable image quality of cervical spine CTs for evaluation of bony structures of cadaveric specimens with different body habitus can be achieved with a reference mAs of 105 at $120 \mathrm{kVp}$ with iterative reconstruction. Pull-down of shoulders during acquisition could improve image quality but may not be feasible in trauma patients with unknown injuries.

ABBREVIATIONS: DLP = dose-length product; FBP = filtered back-projection; $I R=$ iterative reconstruction

C ervical spine CT is routinely used in trauma settings due to its wide availability around the clock and ease of use. ${ }^{1,2}$ Furthermore, it is known to be superior to plain radiographs, which have been reported to fail in the detection of injuries in a substantial number of patients. In a study performed by Mower et al, ${ }^{3}$ injuries were missed on plain radiographs in 320 of 818 patients, most of which were in the lamina or posterior elements. Thus, CT is applied currently in a wide range of patients, even in young ones. ${ }^{1,2}$

Received May 30, 2017; accepted after revision October 23.

From the Clinic of Radiology and Nuclear Medicine (M.T., C.R., D.H., J.L., U.S., S.S., A.H.), University of Basel Hospital, Basel, Switzerland; Department of Diagnostic Radiology (Z.S.-F.), Hospital Centre of Biel, Biel, Switzerland; and Institute of Anatomy (M.M.-G.), University of Basel, Basel, Switzerland.

Please address correspondence to Magdalini Tozakidou, Clinic of Radiology and Nuclear Medicine, University of Basel Hospital, Petersgraben 4, 4031 Basel,

Switzerland; e-mail: magdalini.tozakidou@gmail.com

三 Indicates article with supplemental on-line tables.

http://dx.doi.org/10.3174/ajnr.A5490
The ongoing discussion concerning radiation protection in terms of the as low as reasonably achievable principle demands reduction of the radiation dose down to a level at which image quality is still diagnostically sufficient. ${ }^{4}$ However, the clinically applied dose often relies on manufacturer's recommendations and is not necessarily the lowest possible dose that can be achieved in clinical routine. One important and well-examined role in dose-reduction strategies is using mathematic models such as iterative reconstruction (IR) to reduce image noise and thus allow a lower radiation dose. ${ }^{5}$ The radiation dose for cervical spine CT may vary from one institution to another, depending on the CT scanner and its protocol. The mean radiation dose of the cervical spine in patients of a Canadian emergency department was reported to be $5.7 \mathrm{mSv} .{ }^{6}$ To the best of our knowledge, the lowest possible radiation dose for CT of the cervical spine with sufficient diagnostic value has not been investigated by a systematic stepwise dose reduction. For ethical reasons, a stepwise dose reduc- 
Table 1: Characteristics of cadaveric specimens ${ }^{\mathrm{a}}$

\begin{tabular}{|c|c|c|c|c|c|c|c|}
\hline \multirow{2}{*}{$\begin{array}{l}\text { Cadaveric } \\
\text { Specimen }\end{array}$} & \multirow{2}{*}{$\begin{array}{c}\text { Body } \\
\text { Weight } \\
\text { (kg) }\end{array}$} & \multirow{2}{*}{$\begin{array}{l}\text { Height } \\
\text { (m) }\end{array}$} & \multirow{2}{*}{$\begin{array}{c}\text { BMI } \\
\left(\mathrm{kg} / \mathrm{m}^{2}\right)\end{array}$} & \multirow{2}{*}{$\begin{array}{c}\text { Shoulder } \\
\text { Level }\end{array}$} & \multicolumn{3}{|c|}{$\begin{array}{l}\text { Body Width } \\
(\mathrm{cm}) \text { at Level }\end{array}$} \\
\hline & & & & & C7 & C5 & $\mathrm{C} 3$ \\
\hline 1 & 63 & 1.63 & 23.7 & $\mathrm{C} 5$ & 38.3 & 34.8 & 15.7 \\
\hline 2 & 93 & 1.68 & 33.0 & C5 & 43.4 & 36.0 & 19.0 \\
\hline 3 & 62 & 1.48 & 28.3 & C5 & 37.3 & 32.3 & 15.4 \\
\hline 4 & 94 & 1.62 & 35.6 & $\mathrm{C} 5$ & 46.4 & 39.4 & 16.3 \\
\hline
\end{tabular}

Note:-BMI indicates body mass index.

a Cadavers' body weights included approximately $10-15 \mathrm{~L}$ formalin fixation.

tion cannot be performed in a clinical setting. Therefore, we decided to use cadaveric specimens in the present study.

The aim of the current study was to assess the image quality and diagnostic accuracy of cervical spine CT of cadaveric specimens at different radiation dose levels reconstructed with filtered back-projection (FBP) and an IR algorithm.

\section{MATERIALS AND METHODS \\ Specimens and CT Protocol}

Institutional review board approval was waived. Four human cadaveric specimens ( 2 women, 2 men; age at death, older than 50 years) were prospectively included. The demographics of each specimen are shown in Table 1.

Unenhanced CT scans of the cervical spine were performed on a 128-detector row multidetector CT scanner (Somatom Definition AS+; Siemens, Erlangen, Germany). Cadaveric specimens were in a supine position. Lateral and anteroposterior topograms served as references for the scan range from vertebrae $\mathrm{C} 1$ to $\mathrm{T} 1$. We used the following scan parameters: tube voltage, $120 \mathrm{kV}$ (peak); detector configuration, $128 \times 0.6 \mathrm{~mm}$; pitch factor, 0.8 . The reference tube current-time product ranged from 45 to 355 mAs (45, 75, 105, 135, 150, 165, 195, 275, 355 mAs) by applying automatic tube current modulation (CARE Dose4D; Siemens). The protocol of the tube current-time product was set in steps of $30 \mathrm{mAs}$ between 45 and $195 \mathrm{mAs}$ and in steps of $80 \mathrm{mAs}$ for higher values between 195 and $355 \mathrm{mAs}$ because the difference in image quality is only minor in this range, to our knowledge. Our initial plan was to obtain only scans up to $275 \mathrm{mAs}$. However, scans at that dose seemed unacceptable for the lower C-spine at first glance; thus, we added another $80 \mathrm{mAs}$ to the dose and scanned at $355 \mathrm{mAs}$. Additionally, we included $150 \mathrm{mAs}$ in our protocol to compare our findings with the previously published results of Becce et al. ${ }^{7}$

Images were reconstructed using both a conventional FBP and an IR (sinogram-affirmed iterative reconstruction, strength 3) algorithm as described elsewhere in bone convolution kernels (B70 hours for FBP and I70 hours for IR algorithms, respectively). ${ }^{7-9}$ We used the following image reconstruction parameters: FOV, $15 \times 15 \mathrm{~cm}$ to $21 \times 21 \mathrm{~cm}$ according to the specimen constitution; section thickness/increment, $0.75 / 0.75 \mathrm{~mm}$. Lateral body width was measured on anteroposterior topograms at 3 different heights: C3, C5, and C7 (Fig 1). Shoulder level was defined as the level of the cervical spine, on which the bony shoulder girdle is superimposed on the lateral topogram (Fig 1). For comparison of the height of the shoulder girdle in a clinical setting, topograms of cervical spine CTs of 30 nonintubated patients (15 women, 15 men; mean age, $66.9 \pm 22.7$ years) at the emergency department

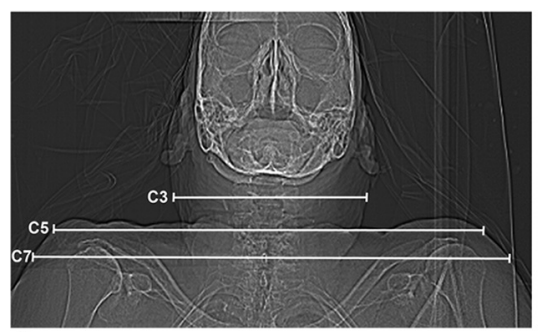

A

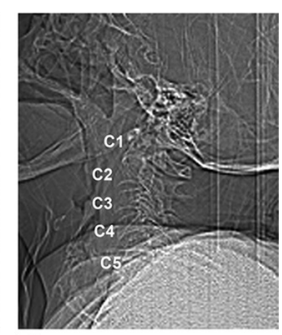

B
FIG 1. Lateral body width was measured on each anteroposterior topogram of the cadaveric specimens at 3 different heights: $\mathrm{C} 3, \mathrm{C} 5$, and $C 7(A)$. On the lateral topogram, the shoulder level of this cadaveric specimen was $C 5(B)$.
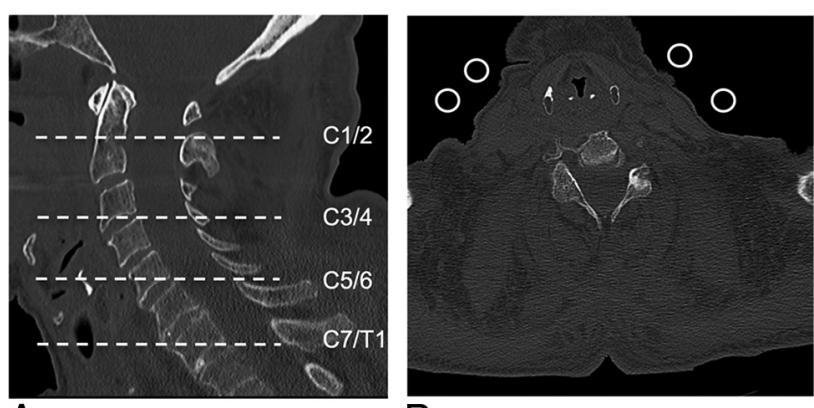
A B

FIG 2. Quantitative and qualitative image noise were evaluated on 4 different cervical spine levels ( $A$, dashed lines). Axial image $(B)$ at level C5-6 shows 4 ROls of $100 \mathrm{~mm}^{2}$ each in the extracorporeal air for quantitative noise measurements.

in 1 week were reviewed by 1 reader. The height of the shoulder girdle was assessed on the lateral topogram and recorded.

\section{Analysis of Radiation Exposure}

The volume CT dose index and the dose-length product (DLP) were automatically generated by the CT unit. The effective dose was estimated by multiplying the DLP by an organ-specific conversion coefficient of $0.0051 \mathrm{mSv} / \mathrm{mGy} \times \mathrm{cm}$ for an adult neck region at $120 \mathrm{kVp} .{ }^{10}$

\section{Analysis of Quantitative Image Noise}

Four circular ROIs of $100 \mathrm{~mm}^{2}$ each at the cervical spine levels (C1-2, C3-4, C5-6, and C7-T1) served for noise measurements. They were placed in the extracorporeal air on axial images at exactly the same level in each scan of the same cadaver by 1 reader with 2 years of experience in spine imaging (Fig 2). Image noise was defined as the SD of the mean CT numbers measured in Hounsfield units within an ROI.

\section{Analysis of Qualitative Image Noise and Morphologic Characteristics}

All CT scans were randomized and independently evaluated by 4 musculoskeletal fellowship-trained radiologists with 2, 3, 4, and 7 years of experience in spine imaging, respectively. Each reader was blinded to the scan parameters and image reconstruction algorithms. Ratings given by the 4 readers were averaged for statistical analysis.

All CT images were displayed with the window level/width set to $600 / 2000$. A total of 72 datasets were assessed using axial and 


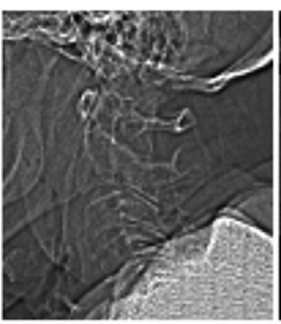

A

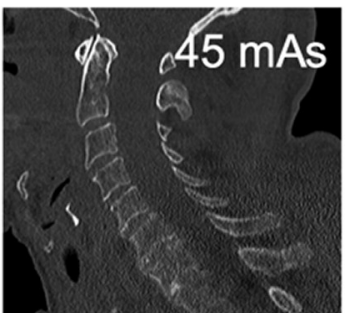

B

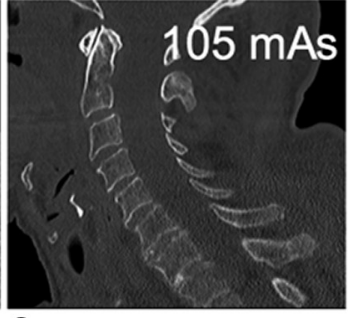

C

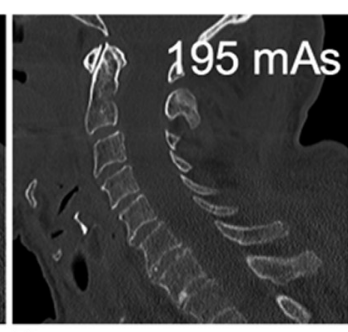

D

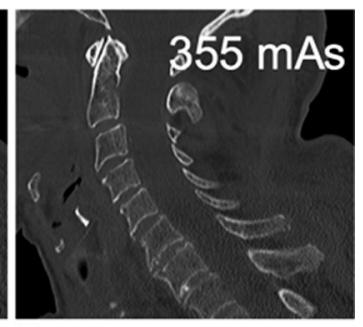

E

FIG 3. Lateral topogram $(A)$ of this cadaveric specimen reveals shoulder height at the $C 5$ level. Sagittal reformatted $C T$ images (B-E; window level/width, 600/2000) of the cervical spine at 45, 105, 195, and $355 \mathrm{mAs}$ reconstructed with sonogram-affirmed iterative reconstruction (strength level, 3) using bone convolution kernels show a decreasing image noise with increasing tube currents, but still sufficient image quality at $105 \mathrm{mAs}$ compared with $355 \mathrm{mAs}$.

\begin{tabular}{|c|c|c|}
\hline Assessment, Localization & Score & Criteria \\
\hline \multicolumn{3}{|l|}{ Cortex } \\
\hline \multirow[t]{3}{*}{ Vertebral body (sag/ax) } & 0 & Not visible \\
\hline & 1 & $\begin{array}{l}\text { Visible, but not } \\
\text { analyzable }\end{array}$ \\
\hline & 2 & Clearly visible \\
\hline \multirow[t]{3}{*}{ Facet joint (sag) } & 0 & Not visible \\
\hline & 1 & $\begin{array}{l}\text { Visible, but not } \\
\text { analyzable }\end{array}$ \\
\hline & 2 & Clearly visible \\
\hline \multicolumn{3}{|l|}{ Trabeculae } \\
\hline \multirow[t]{2}{*}{ Vertebral body (sag) } & 0 & Not visible \\
\hline & 1 & Clearly visible \\
\hline \multicolumn{3}{|l|}{ Integrity } \\
\hline \multirow[t]{2}{*}{ Anterior vertebral body line (sag) } & 0 & Not visible \\
\hline & 1 & Clearly visible \\
\hline \multirow[t]{2}{*}{ Posterior vertebral body line (sag) } & 0 & Not visible \\
\hline & 1 & Clearly visible \\
\hline \multicolumn{3}{|l|}{ Alignment } \\
\hline \multirow[t]{2}{*}{ Vertebral body (sag) } & 0 & Not visible \\
\hline & 1 & Clearly visible \\
\hline \multirow[t]{2}{*}{ Facet joint (sag) } & 0 & Not visible \\
\hline & 1 & Clearly visible \\
\hline Maximal sum & 9 & \\
\hline
\end{tabular}

Note:- -sag indicates sagittal reformations; ax, axial reformations.

${ }^{a}$ Cortex, trabeculae, and integrity were assessed on each cervical vertebral segment (eg, C3); alignment was assessed on each cervical level (eg, C3-4). The least visible cortices of each vertebral body and facet joint were used for this analysis.

sagittal reformations in OsiriX, Version 4.1.2 (http:// www.osirixviewer.com). Qualitative image noise was graded on a 3-point scale $(1=$ no noise, $2=$ acceptable minor noise, $3=$ unacceptable major noise) on 4 levels: C1-2, C3-4, C5-6, and C7-T1 using sagittal reformations (Figs $2 \mathrm{~A}$ and 3 ). Morphologic characteristics of the bony structures were analyzed on a Likert scale. On each cervical segment (eg, C3), the cortex, trabeculae, and integrity of the anterior and posterior vertebral body lines were assessed; on each cervical level (eg, C3-4), alignment was assessed on either a 2- or a 3-point scale as shown in Table 2.

\section{Statistical Analysis}

Quantitative and qualitative parameters were compared using analysis of variance for repetitive measurements and the Tukey test. Statistical tests were performed using appropriate statistical software (Statistica 7, StatSoft, Tulsa, Oklahoma; MedCalc for Windows, MedCalc Software, Mariakerke, Belgium). A P value $<$
Table 3: Effective tube current at different cervical spine levels ${ }^{\mathrm{a}}$

\begin{tabular}{lcccc}
\hline $\begin{array}{c}\text { Applied } \\
\text { Tube Current } \\
\text { (mAs) }\end{array}$ & \multicolumn{4}{c}{ Effective Tube Current (mAs) } \\
\cline { 2 - 5 } & C1-2 & C3-4 & C5-6 & C7-T1 \\
\hline 45 & $37 \pm 4$ & $46 \pm 3$ & $45 \pm 3$ & $43 \pm 2$ \\
75 & $62 \pm 7$ & $78 \pm 4$ & $76 \pm 2$ & $70 \pm 3$ \\
105 & $88 \pm 8$ & $110 \pm 6$ & $106 \pm 5$ & $99 \pm 3$ \\
135 & $113 \pm 13$ & $139 \pm 8$ & $133 \pm 9$ & $127 \pm 6$ \\
150 & $126 \pm 13$ & $155 \pm 10$ & $149 \pm 6$ & $142 \pm 6$ \\
165 & $138 \pm 14$ & $170 \pm 9$ & $160 \pm 6$ & $157 \pm 5$ \\
195 & $163 \pm 16$ & $204 \pm 11$ & $190 \pm 6$ & $186 \pm 7$ \\
275 & $234 \pm 23$ & $280 \pm 18$ & $270 \pm 19$ & $257 \pm 12$ \\
355 & $331 \pm 27$ & $344 \pm 49$ & $343 \pm 14$ & $336 \pm 13$ \\
\hline
\end{tabular}

${ }^{a}$ Data represent mean \pm SD at the respective cervical spine levels.

.05 was considered statistically significant. Because a high shoulder position in the cadaveric specimens led to remarkably higher image noise and lower image quality at the levels C5$\mathrm{T} 1$, upper cervical levels (C1-4) with no shoulder girdle superimposition were additionally separately analyzed. Interobserver agreement was assessed by calculating the Kendall coefficient of concordance.

\section{RESULTS}

\section{Analysis of Radiation Exposure}

The radiation dose output given by the volume CT dose index and DLP showed a linear relation to the applied tube current. The mean volume CT dose index, DLP, and effective dose were 26.5 $\mathrm{mGy}, 530 \mathrm{mGy} \times \mathrm{cm}$, and $2.7 \mathrm{mSv}$ for the highest applied reference $\mathrm{mAs}$ value at $355 \mathrm{mAs}$ and $3.3 \mathrm{mGy}, 65 \mathrm{mGy} \times \mathrm{cm}$, and 0.3 $\mathrm{mSv}$ for the lowest applied reference $\mathrm{mAs}$ value at $45 \mathrm{mAs}$, respectively. The effective $\mathrm{mAs}$ ranged from $46 \mathrm{mAs}$ (for reference $\mathrm{mAs}$ of 45) to $408 \mathrm{mAs}$ (for reference mAs of 355). Detailed ranges of effective $\mathrm{mAs}$ for the 4 different cadavers were the following (reference mAs in parentheses): 46-51 mAs (45), 77-86 mAs (75), 105-121 mAs (105), 131-157 mAs (135), 146-172 mAs (150), 161-192 mAs, (165), 195-225 mAs (195), 267-321 mAs (275), and 347-408 mAs (355). For details see Table 3.

\section{Analysis of Quantitative Image Noise}

Comparison of quantitative noise measurements in images with IR and FBP reconstructions showed significantly less noise in images with IR than in images with FBP (mean noise in air C1-T1: IR, $30 \mathrm{HU}$; FBP, $52 \mathrm{HU}$; $P<.001$ ). As expected, image noise decreased as tube current increased in both IR and FBP reconstructions. With iterative reconstructions, only images with a tube 

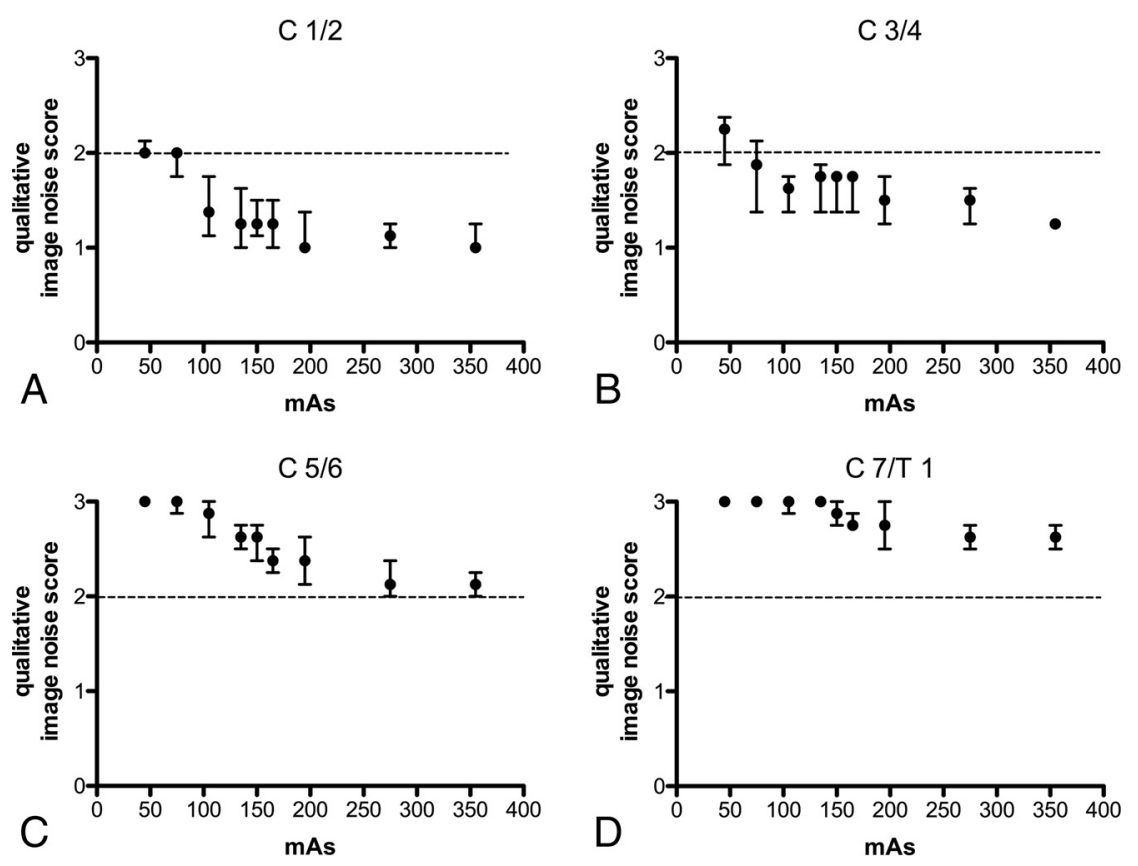

FIG 4. Qualitative image noise for iterative reconstructed images was evaluated on each cervical spine level using a noise score scale (1, no noise; 2 , minor noise acceptable [dashed line, $A-D] ; 3$, major noise, unacceptable). The median image noise was at least acceptable at levels $\mathrm{Cl}-2(A)$ with each tube current and at $75 \mathrm{mAs}$ at levels $\mathrm{C} 3-4(B)$, but unacceptable at levels $\mathrm{C5}-\mathrm{Tl}(C$ and $D)$, except for $355 \mathrm{mAs}$ at $\mathrm{C5}-6$ (C). Data are median and 25th to 75th percentiles.
C 1- T1

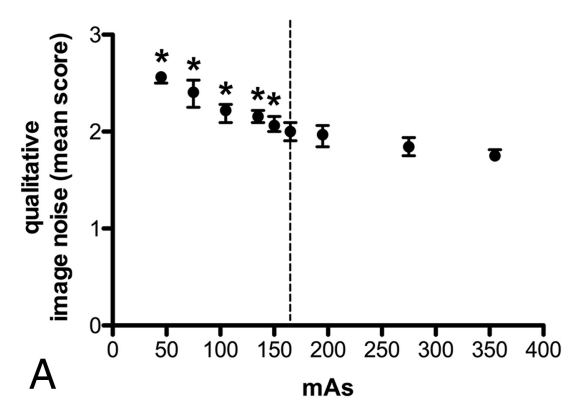

C $1-4$

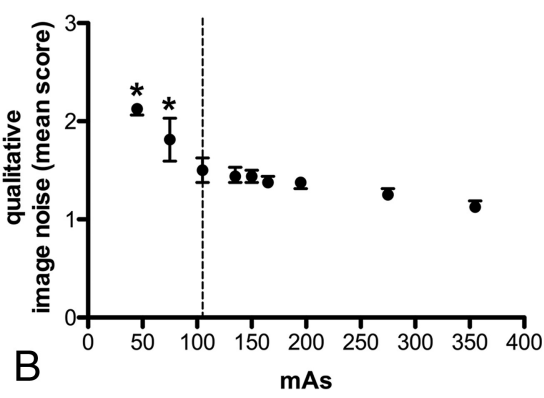

FIG 5. Grouped analysis of qualitative image noise shows significant differences at $\leq 150 \mathrm{mAs}$ with $355 \mathrm{mAs}$ for all cervical spine levels $(45 \mathrm{mAs}, P<.001 ; 75 \mathrm{mAs}, P<.001 ; 105 \mathrm{mAs}, P=.0006$; $135 \mathrm{mAs}, P=.0019 ; 150 \mathrm{mAs}, P=.039)(A)$. Significant differences in image quality for levels $\mathrm{Cl}-4$, which were not superimposed by the shoulder girdle, were found for scans with $\leq 75 \mathrm{mAs}$ (45 $\mathrm{mAs}, P<.001 ; 75 \mathrm{mAs}, P<.001)$ compared with $355 \mathrm{mAs}(B)$. The dashed lines in $A$ and $B$ represent the lowest tube currents ( $165 \mathrm{mAs}$ for $\mathrm{Cl}-\mathrm{Tl}$ and $105 \mathrm{mAs}$ for $\mathrm{Cl}-4)$ that are not significantly different with respect to qualitative image noise compared with $355 \mathrm{mAs}$. Asterisks indicate values that are significantly different compared with $355 \mathrm{mAs}(P<.05)$. Dots and bars indicate median and 25th to 75th percentiles.

current of $45 \mathrm{mAs}$ showed a significant decrease in quantitative image noise compared with the highest applied tube current of $355 \mathrm{mAs}$ at levels C1-4 when analyzing each cervical segment independently. When we summarized all cervical spine levels, no statistically significant difference of image noise was noted between IR images in scans at 75 and 355 mAs, whereas scans at 45 $\mathrm{mAs}$ showed higher image noise compared with scans at $355 \mathrm{mAs}$ $(P=.010)$. Analysis of the upper cervical spine $(\mathrm{C} 1-4)$ revealed no significant difference in image noise in IR images in scans at 105 and $355 \mathrm{mAs}$, whereas scans at $75 \mathrm{mAs}(P=.004)$ and $45 \mathrm{mAs}$ $(P<.001)$ showed significantly higher image noise compared with scans at $355 \mathrm{mAs}$.

\section{Analysis of Qualitative Image Noise and Morphologic Characteristics}

Overall, qualitative image quality was significantly better with IR than with FBP (noise score, $P=.03$; morphologic score, $P<.001$ ), even though morphologic characteristics only showed slight differences between IR and FBP (mean: IR, 44.6 \pm 5.0; FBP, $43.3 \pm 5.3$; median: [25th to 75th percentile] IR, 44.8 [42.1/ 48.4]; FBP, 44.3 [39.8/47.6]).

Detailed results for iterative reconstructions are illustrated in Figs 4-6. In comparison with FBP reconstruction, IR images allow a higher reduction of the radiation dose (Table 4).

Regarding qualitative image noise, all scans with any reference tube current-time product for IR images at 105 $\mathrm{mAs}$ or higher were rated as acceptable or better at levels C1-2 and C3-4. In contrast, more than half of the scans at levels C5-6 and almost all scans at level C7-T1 were rated as not acceptable for all tube current-time products, even with the highest reference $\mathrm{mAs}$ value of 355 (median: C5-6 = 2.1 and C7-T1 = 2.6; Fig 4). When we grouped all cervical spine levels together, statistical analysis revealed a significant difference for qualitative image noise with the IR of scans at $\leq 150 \mathrm{mAs}$ compared with scans at $355 \mathrm{mAs}$ (45 mAs, $P<.001 ; 75 \mathrm{mAs}$, $P<.001 ; 105 \mathrm{mAs}, P=.0006 ; 135 \mathrm{mAs}$, $P=.002 ; 150 \mathrm{mAs}, P=.04$; Fig $5 A$ ). FBP analyses of qualitative image noise showed significant differences at $\leq 195$ mAs (FBP) compared with 355 mAs (IR; $P=.012)$. The Kendall coefficient of interobserver agreement for image noise was good with 0.67 .

The height of the shoulders was at the C5 level in all cadavers. Hence, body width was larger at lower spine levels compared with the upper levels (Table 1). For comparison, in a clinical setting at the emergency department, the shoulder height of 30 patients was only slightly lower (C5-T1) than in the cadaveric specimens with 4 shoulders at C5, 12 at C6, and 7 each at C7 and $\mathrm{T} 1$, respectively.

Morphologic characteristics of images with IR were rated slightly better than with FBP reconstructions $(P=.001)$. For IR images, grouped scores for all levels revealed no statistically significant difference between 105 and $355 \mathrm{mAs}$, but significantly lower scores at $75 \mathrm{mAs}(P=.03)$ and $45 \mathrm{mAs}(P<.001)$. Morphologic characteristics of the upper spine $(\mathrm{C} 1-4)$ showed no significant difference between 45 and 355 mAs. Single analysis of 
cortex visibility showed no significant difference for the upper cervical spine (C1-4), but significantly lower scores at $45 \mathrm{mAs}$ $(P=.001)$ when examining the entire cervical spine. Scores for trabeculae were significantly different at $45 \mathrm{mAs}$ for the upper $(P=.03)$ and the entire cervical spine $(P=.003$; On-line Table 1$)$. Analysis of morphologic scores with FBP reconstructions are shown in On-line Tables 1 and 2. Interobserver agreement for morphologic characteristics was excellent with a Kendall coefficient of 0.848 .

If we take the results of qualitative image noise and morphologic score analysis together, the image quality proved to be sufficient with a tube current of $105 \mathrm{mAs}$ and iterative reconstructions for cervical spine levels, which are not superimposed by the shoulders.

\section{DISCUSSION}

CT image quality of the cervical spine in cadaveric specimens was superior with the IR compared with the FBP algorithm; this finding implies that the CT dose may be reduced when applying IR protocols in clinical practice. This result is in accordance with the literature and pertains to not only musculoskeletal imaging but also thoracic and abdominal imaging. ${ }^{7,11-13}$ FBP algorithms may lead to noisy images in low-dose protocols or obese patients. ${ }^{14,15}$ Reported benefits of IR algorithms include a reduced noise level with enhanced subjective and objective image quality as well as reduction of the radiation dose with preserved image quality. ${ }^{12}$ However, Becce et $\mathrm{al}^{7}$ emphasized the restricted benefit of the IR

C 1-7

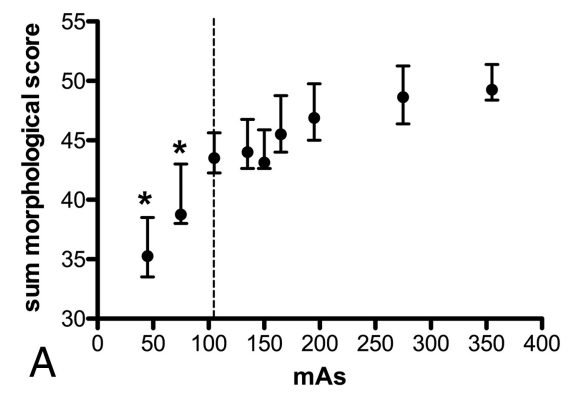

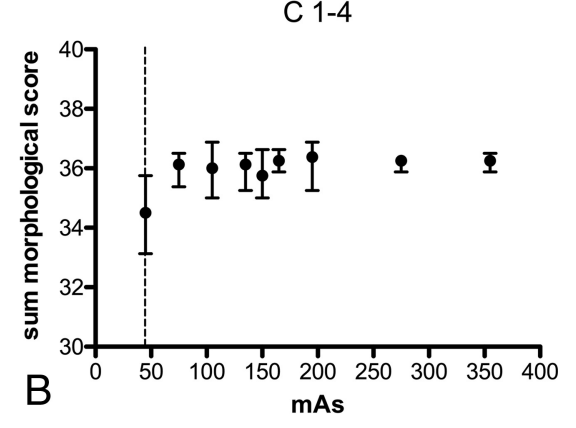

FIG 6. Analysis of morphologic characteristics for iterative reconstructed images shows significant impaired image quality with $75 \mathrm{mAs}(P=.0249)$ and $45 \mathrm{mAs}(P=.0002)$ compared with 355 $\mathrm{mAs}$ for all cervical spine levels $(A)$. The dashed line $(A)$ at $105 \mathrm{mAs}$ represents the lowest value that is not significantly different in image quality compared with $355 \mathrm{mAs}$ and can be recommended as the lowest tube current value with sufficient image quality. Analysis of cervical spine levels 1-4, which are not superimposed by the shoulders, shows no significant difference in image quality with any tube current compared with $355 \mathrm{mAs}(B)$. Asterisks indicate values that are significantly different compared with $355 \mathrm{mAs}(P<.05)$. Dots and bars indicate median and 25th to 75th percentiles. algorithm in analyzing trabecular bone structures in contrast to the discs or ligaments in cervical spine imaging, though overall image quality was superior using IR. This finding is in line with our results of morphologic characteristics on bony structures, which showed only subtle differences between IR- and FBP-reconstructed images and might be because spatial resolution depends on several factors, including image thickness, image matrix, voxel size, and FOV. The IR technique is not capable of compensating for image noise in very low tube currents due to photon starvation, which explains the unacceptable image quality at lower cervical spine levels.

Qualitative noise analysis revealed sufficient image quality for CT of the cervical spine by applying a reference tube current-time product of $165 \mathrm{mAs}$ and $120 \mathrm{kVp}$ with the IR algorithm. If we focused on the upper cervical spine (C1-4), which was not superimposed by the shoulder girdle, all scans at $105 \mathrm{mAs}$ showed a sufficient image quality. Considering morphologic criteria, such as trabecular and cortical structures, even a reference tube current-time product as low as $105 \mathrm{mAs}$ was satisfying. Our findings are in accordance with previously published results from Becce et al, ${ }^{7}$ who demonstrated that the low-dose protocol of the cervical spine is feasible at a reference level of $150 \mathrm{mAs}$. They compared a standard dose protocol at $275 \mathrm{mAs}$ with a low-dose protocol of $150 \mathrm{mAs}$, each at a fixed tube current of $120 \mathrm{kVp} .^{7}$ Several studies mpared protocols at different tube current-time products $^{7,16,17}$; however, no tube current-time product lower than 150 $\mathrm{mAs}$ for CT of the cervical spine has been published so far, to our knowledge.

If we excluded cervical spine levels that are superimposed by shoulders, a further reduction of the tube currenttime product to $105 \mathrm{mAs}$ still revealed sufficient image quality in the analysis of the cervical spine.

Our results show that even very low dose protocols with $105 \mathrm{mAs}$ do not impair image quality of the cervical spine. However, superimposition of the shoulder girdle proved to be a limitation of a further reduction of the dose. We demonstrated that image quality of the cervical spine at levels above the shoulder girdle is sufficient with a tube current of $45 \mathrm{mAs}$ at level C1-2 and with a tube current of $75 \mathrm{mAs}$ at level C3-4. This

Table 4: Minimum required dose for at least sufficient qualitative image quality of the cervical spine in IR and FBP images compared with 355 mAs (IR)

\begin{tabular}{|c|c|c|c|c|}
\hline & \multicolumn{2}{|c|}{ Levels $\mathrm{Cl}-\mathrm{Tl}$} & \multicolumn{2}{|c|}{ Levels $\mathrm{Cl}-4$} \\
\hline & IR & FBP & IR & FBP \\
\hline Image noise score & $\begin{array}{l}165 \mathrm{mAs} \\
\mathrm{DLP}=250 \mathrm{mGy} \times \mathrm{cm} \\
\mathrm{ED}=1.3 \mathrm{mSv}\end{array}$ & $\begin{array}{l}275 \mathrm{mAs} \\
\mathrm{DLP}=412 \mathrm{mGy} \times \mathrm{cm} \\
\mathrm{ED}=2.1 \mathrm{mSv}\end{array}$ & $\begin{array}{l}105 \mathrm{mAs} \\
\mathrm{DLP}=160 \mathrm{mGy} \times \mathrm{cm} \\
\mathrm{ED}=0.8 \mathrm{mSv}\end{array}$ & $\begin{array}{l}150 \mathrm{mAs} \\
\mathrm{DLP}=225 \mathrm{mGy} \times \mathrm{cm} \\
\mathrm{ED}=1.1 \mathrm{mSv}\end{array}$ \\
\hline Morphologic characteristics score & $\begin{array}{l}105 \mathrm{mAs} \\
\mathrm{DLP}=160 \mathrm{mGy} \times \mathrm{cm} \\
\mathrm{ED}=0.8 \mathrm{mSv}\end{array}$ & $\begin{array}{l}105 \mathrm{mAs} \\
\mathrm{DLP}=160 \mathrm{mGy} \times \mathrm{cm} \\
\mathrm{ED}=0.8 \mathrm{mSv}\end{array}$ & $\begin{array}{l}45 \mathrm{mAs} \\
\mathrm{DLP}=65 \mathrm{mGy} \times \mathrm{cm} \\
\mathrm{ED}=0.3 \mathrm{mSv}\end{array}$ & $\begin{array}{l}45 \mathrm{mAs} \\
\mathrm{DLP}=65 \mathrm{mGy} \times \mathrm{cm} \\
\mathrm{ED}=0.3 \mathrm{mSv}\end{array}$ \\
\hline
\end{tabular}

Note:-ED indicates effective dose.

${ }^{a}$ Data presented are the lowest applied tube current-time product at which scans showed no statistically significant differences in image quality compared with scans at the highest applied tube current-time product ( $355 \mathrm{mAs}$ IR). Dose-length product and estimated effective dose are shown for each applied tube current-time product. 
result is in line with a study performed by Kranz et al, ${ }^{18}$ who reported the importance of lowering both shoulders during CT of the cervical spine in patients with and without the use of CT table straps. At lower cervical spine levels, the radiation absorption was high due to superimposing the shoulder girdle, and image quality proved to be insufficient for most scans at these specific levels, even at the highest applied dose. Even in our small sample size of 30 patients who had a CT of the cervical spine in an emergency setting without attention being paid to the shoulder position during the scan, the shoulder girdle was at the level of C5-T1. Pulldown of the shoulders can be simple and efficient for low-dose CT of the cervical spine and should be performed whenever feasible. We believe the shoulder position is more relevant than the body mass index because the body mass index of our cadaveric specimens varied and ranged from 24 to $36 \mathrm{~kg} / \mathrm{m}^{2}$.

Reducing the reference tube current-time product of 275 mAs, which is recommended by the manufacturer for cervical spine imaging, to $105 \mathrm{mAs}$ at $120 \mathrm{kV}$ p reduces the effective dose by $62 \%$ from 2.1 to $0.8 \mathrm{mSv}$. With this low-dose CT protocol of the cervical spine, the effective dose is as low as the effective dose of 2 plain radiographs, which have been reported to be between 0.1 and $1 \mathrm{mSv} .{ }^{19}$ Geyer et al ${ }^{19}$ compared FBP images with adaptive statistical iterative reconstructions on 2 different 64-row multidetector CT systems (Light Speed VCT XT and Discovery CT 750HD; GE Healthcare, Milwaukee, Wisconsin) using a tube voltage of $120 \mathrm{kVp}$ and automatic tube current modulation. Similarly, they could show that scanning with adaptive statistical iterative reconstructions at an estimated effective dose of $1.1 \mathrm{mSv}$ is possible. ${ }^{19}$ It is well-known that fractures of the cervical spine can be missed on radiographs. ${ }^{20,21}$ Therefore, low-dose CT may be preferred over radiographs in settings of the cervical spine trauma.

The effects of changes of tube voltage on cervical spine CT were examined in a phantom study of Hoang et al. ${ }^{22}$ Their study revealed that reducing the voltage from 120 to $80 \mathrm{kVp}$ for neck CT can result in a 50\% reduction in the absorbed organ dose to the bone marrow of the cervical spine and mandible, without impairment in subjective image quality. ${ }^{22}$ However, in clinical settings, reduction of tube voltage down to $70 \mathrm{kVp}$ seems to be diagnostic for soft-tissue evaluation but not necessarily for the cervical spine. ${ }^{23}$ On the other hand, a lesser reduction of tube voltage to $100 \mathrm{kV}$ showed a substantial reduction of the radiation dose with a small increase in objective image noise, but without differences in subjective image quality. ${ }^{17}$ In another study, Gleeson et $\mathrm{al}^{24}$ used a higher kilovolt peak of 140 in a whole-body skeletal CT and reported dose reduction as a result of consecutive reduction of the tube current. Thus, additional dose reduction may be applicable with changes of tube voltage in addition to our applied tube current changes. We focused on bony structures in an emergency trauma setting without the use of intravenous contrast media; therefore, the beneficial effect of low kilovolt peak levels are negligible. High kilovolt peak levels have been suggested to be less susceptible to variations in body mass ${ }^{24}$ and might improve image quality of the lower cervical spine, which is impaired by the shoulders. However, further studies are needed to support this hypothesis.

Our study has several limitations. First, formalin fixation of our cadaveric specimens hampered a low shoulder position. Thus, cervical spine levels C5-T1 were superimposed by the shoulder girdle in all cadaveric specimens. We addressed this limitation in analyzing levels C1-4 separately. Second, formalin fixation might cause a change in radiation attenuation due to bone demineralization. ${ }^{25}$ Third, because we applied automatic tube current modulation in the current study, the technical parameters could not be transferred automatically to the protocols of other CT machines. Fourth, we measured only noise in air, which might not be representative of noise in bone. However, measurements in soft tissue or the spinal cord were performed but were widely scattered; we attributed this feature to formalin fixation and insufficient distinguishability of the spinal cord from CSF. Fifth, no measurement of spatial resolution was performed. Sixth, the number of examined cadavers was small, hampering a meaningful comparison with respect to noise measurements. However, the published CT dose index values of our study can also be used to optimize the protocols of our vendor by using automatic tube current modulation.

\section{CONCLUSIONS}

Taking results from morphologic scores and image quality together, we conclude that clinically acceptable image quality of cervical spine CT for evaluation of bony structures of cadaveric specimens with variable body habitus can be achieved with a reference $\mathrm{mAs}$ as low as 105 at $120 \mathrm{kVp}$ with IR. The high position of the shoulders is a limiting factor, even with high radiation doses. Pull-down of both shoulders during acquisition could improve image quality but may not be feasible in the trauma patient with unknown injuries.

\section{ACKNOWLEDGMENTS}

The authors thank our CT technician Geraldine Stadelmann for her excellent assistance in CT data acquisition.

\section{REFERENCES}

1. Daffner RH, Hackney DB. ACR Appropriateness Criteria on suspected spine trauma. J Am Coll Radiol 2007;4:762-75 CrossRef Medline

2. Saketkhoo DD, Bhargavan M, Sunshine JH, et al. Emergency department image interpretation services at private community hospitals. Radiology 2004;231:190-97 CrossRef Medline

3. Mower WR, Hoffman JR, Pollack CV Jr, et al; NEXUS Group. Use of plain radiography to screen for cervical spine injuries. Ann Emerg Med 2001;38:1-7 CrossRef Medline

4. Jaju A, Shaw HL, Don S, et al. ALARA: impact of practice quality improvement initiative on dose reduction in pediatric voiding cystourethrogram. AJR Am J Roentgenol 2015;205:886-93 CrossRef Medline

5. Ghetti C, Palleri F, Serreli G, et al. Physical characterization of a new CT iterative reconstruction method operating in sinogram space. J Appl Clin Med Phys 2013;14:4347 CrossRef Medline

6. Worrall JC, Jama S, Stiell IG. Radiation doses to emergency department patients undergoing computed tomography. CJEM 2014;16: 477-84 CrossRef Medline

7. Becce F, Ben Salah Y, Verdun FR, et al. Computed tomography of the cervical spine: comparison of image quality between a standarddose and a low-dose protocol using filtered back-projection and iterative reconstruction. Skeletal Radiol 2013;42:937-45 CrossRef Medline

8. Moscariello A, Takx RA, Schoepf UJ, et al. Coronary CT angiography: image quality, diagnostic accuracy, and potential for 
radiation dose reduction using a novel iterative image reconstruction technique-comparison with traditional filtered back-projection. Eur Radiol 2011;21:2130-38 CrossRef Medline

9. Winklehner A, Karlo C, Puippe G, et al. Raw data-based iterative reconstruction in body CTA: evaluation of radiation dose saving potential. Eur Radiol 2011;21:2521-26 CrossRef Medline

10. Deak PD, Smal Y, Kalender WA. Multisection CT protocols: sex-and age-specific conversion factors used to determine effective dose from dose-length product. Radiology 2010;257:158-66 CrossRef Medline

11. Schindera ST, Diedrichsen L, Müller HC, et al. Iterative reconstruction algorithm for abdominal multidetector $\mathrm{CT}$ at different tube voltages: assessment of diagnostic accuracy, image quality, and radiation dose in a phantom study. Radiology 2011;260:454-62 CrossRef Medline

12. Willemink MJ, Leiner $\mathrm{T}$, de Jong $\mathrm{PA}$, et al. Iterative reconstruction techniques for computed tomography part 2: initial results in dose reduction and image quality. Eur Radiol 2013;23:1632-42 CrossRef Medline

13. Gervaise A, Osemont B, Lecocq S, et al. CT image quality improvement using Adaptive Iterative Dose Reduction with widevolume acquisition on 320-detector CT. Eur Radiol 2012;22:295301 CrossRef Medline

14. Pan X, Sidky EY, Vannier M. Why do commercial CT scanners still employ traditional, filtered back-projection for image reconstruction? Inverse Probl 2009;25:1230009 Medline

15. Nelson RC, Feuerlein S, Boll DT. New iterative reconstruction techniques for cardiovascular computed tomography: how do they work, and what are the advantages and disadvantages? J Cardiovasc Comput Tomogr 2011;5:286-92 CrossRef Medline

16. Wirth S, Meindl T, Treitl M, et al. Comparison of different patient positioning strategies to minimize shoulder girdle artifacts in head and neck CT. Eur Radiol 2006;16:1757-62 CrossRef Medline

17. Mulkens TH, Marchal P, Daineffe S, et al. Comparison of low-dose with standard-dose multidetector $\mathrm{CT}$ in cervical spine trauma. AJNR Am J Neuroradiol 2007;28:1444-50 CrossRef Medline

18. Kranz PG, Wylie JD, Hoang JK, et al. Effect of the CT table strap on radiation exposure and image quality during cervical spine CT. AJNR Am J Neuroradiol 2014;35:1870 -76 CrossRef Medline

19. Geyer LL, Körner M, Hempel R, et al. Evaluation of a dedicated MDCT protocol using iterative image reconstruction after cervical spine trauma. Clin Radiol 2013;68:e391-396 CrossRef Medline

20. Woodring JH, Lee C. Limitations of cervical radiography in the evaluation of acute cervical trauma. J Trauma 1993;34:32-39 CrossRef Medline

21. Acheson MB, Livingston RR, Richardson ML, et al. High-resolution CT scanning in the evaluation of cervical spine fractures: comparison with plain film examinations. AJR Am J Roentgenol 1987;148: 1179-85 CrossRef Medline

22. Hoang JK, Yoshizumi TT, Nguyen G, et al. Variation in tube voltage for adult neck MDCT: effect on radiation dose and image quality. AJR Am J Roentgenol 2012;198:621-27 CrossRef Medline

23. Gnannt R, Winklehner A, Goetti R, et al. Low kilovoltage CT of the neck with $70 \mathrm{kVp}$ : comparison with a standard protocol. AJNR AmJ Neuroradiol 2012;33:1014-19 CrossRef Medline

24. Gleeson TG, Byrne B, Kenny P, et al. Image quality in low-dose multidetector computed tomography: a pilot study to assess feasibility and dose optimization in whole-body bone imaging. Can Assoc Radiol J 2010;61:258-64 CrossRef Medline

25. Fonseca AA, Cherubini K, Veeck EB, et al. Effect of $10 \%$ formalin on radiographic optical density of bone specimens. Dentomaxillofac Radiol 2008;37:137-41 CrossRef Medline 